\title{
Risk factors for campylobacter infection in infants and young children: a matched case-control study
}

\author{
T. D. TENKATE AND R. J. STAFFORD* \\ Brisbane Southside Public Health Unit, Queensland Health, Australia
}

(Accepted 27 July 2001)

\section{SUMMARY}

Campylobacter infection has one of the highest rates of all the notifiable diseases in Australia, with a peak in children aged 0-35 months. A matched case-control study was conducted to investigate risk factors for campylobacter infection for children in this age group. Eighty-one cases and 144 controls were enrolled in the study that was conducted between 24 January 1996 and 21 January 1997. The following risk factors were found to be independently associated with illness: ownership of pet puppies (adjusted odds ratio [OR] 16.58, 95\% confidence interval [CI] 3.73-73.65) and pet chickens (OR 11.80, CI 1.37-101.75), and consumption of mayonnaise (OR $4 \cdot 13$, CI $1 \cdot 61-10 \cdot 59$ ). We propose that children aged less than 3 years are at risk of campylobacter infection if residing in a household which has puppies or chickens as pets.

\section{INTRODUCTION}

In Australia, there are over 10000 notifications of campylobacter infection each year, and campylobacteriosis consistently has one of the highest annual rates of all notifiable diseases (1998 notification rate $=108 \cdot 3$ cases per 100000 population) [1]. This high notification rate for campylobacter infection also occurs in other western countries, along with a seasonal trend of higher notifications in summer, a slightly higher notification rate for males compared to females, and a bimodal age distribution with a major peak in the 0-4 year age group [2].

The majority of cases of campylobacter infection are sporadic, with outbreaks less common. Most of the outbreaks have been linked to the consumption of raw milk or contaminated water [2]. A number of case-control studies have investigated sporadic cases, and have identified the following general risk factors: handling raw poultry [3]; consumption of chicken [3-6], and in particular undercooked chicken [6-9]; consumption of raw milk [7], or milk from bottles with bird-pecked tops [5]; consumption of untreated

\footnotetext{
* Author for correspondence: Brisbane Southside Public Health Unit, P.O. Box 333, Archerfield, QLD, 4108, Australia.
}

water $[7,8,10]$; contact with dogs or puppies $[4,5,7]$ and cats or kittens $[6,8]$, and in particular pets with diarrhoea $[10,11]$; and travel abroad $[5,7]$.

When we reviewed local campylobacter notification data in a previous study, we found significantly higher rates of notification for the $0-2$ year age group, and in particular for those children aged 12-23 months. In addition, for the factors geographic distribution and socioeconomic status, trends observed in other age groups were not observed for the $0-4$ years age group [12]. This suggests that factors which influence notification rates in the general community may not have the same influence for infants and young children.

Risk factors associated with campylobacter infection in infants and young children have been investigated in a limited number of studies. We have located only two published analytic studies and both were conducted in developing countries. These studies found that exposure to live chickens within the household or the keeping of fowl [13, 14] and contaminated drinking water [13] were factors associated with illness. However, controls in both studies were selected from hospital patients with campylobacter-negative diarrhoeal stools, rather than 
healthy community controls, and in one study [13] more than half the cases were co-infected with other known faecal pathogens.

This paper describes a matched case-control study conducted in Queensland, Australia, to investigate risk factors for sporadic campylobacter infection in infants and young children (aged 0-2 years).

\section{METHODS}

\section{Study design}

A matched case-control study was conducted in the predominantly urban Brisbane Southside and South Coast areas of Queensland (1996 estimated resident population, $1 \cdot 1$ million) and data were collected over a 12 month period between 24 January 1996 and 21 January 1997. Sporadic cases of camplyobacter infection in infants and young children were identified through the routine notification of diseases by pathology laboratories, with a network of general practitioners and hospitals providing earlier referral of possible cases. Control subjects were healthy volunteers obtained through community-based Child Health Clinics in the study area. Personal interviews were conducted by a single project officer, and due to the age of the study subjects, these were with a parent or guardian. A standard questionnaire was used to obtain information on the child's exposures in the 7 days prior to illness or interview (for controls).

\section{Cases}

A case was defined as a child aged $0-35$ months with a positive stool result (for Campylobacter jejuni or $C$. coli) and the following symptoms: diarrhoea (two or more loose stools in $24 \mathrm{~h}$ ), plus one or more of abdominal pain, fever, malaise or vomiting. The cases had to reside in the study area and the stool sample indicate no other enteric pathogens. Cases were excluded if: the case was part of an outbreak (two or more associated cases), another member of the household or a close contact had been diagnosed with campylobacter infection in the 2 months prior to the cases' illness, if the case was a known carrier, or if matching controls could not be located. Cases were also excluded if not interviewed within 1 month of onset of illness.

\section{Controls}

An attempt was made to match two controls with each case. Subjects were matched by age $( \pm$ three months), sex and general geographical location (postcode) of the case's residence. If more than two controls met the matching criteria, the two controls with dates of birth closest to the case were selected. Controls were excluded if: they had suffered diarrhoea in the 14 days prior to interview, reported a past history of campylobacter infection, or were otherwise immuno-compromised. If repeated attempts failed to contact one of the selected controls, or if after initial screening the control did not meet the inclusion criteria, the next most eligible control was selected for interview. Interviews were conducted as soon as possible after the corresponding case interview, with all controls interviewed within 1 month of the corresponding case interview.

\section{Questionnaire}

The questionnaire was developed through involvement of focus groups of mothers with young children, and piloted prior to use in the study. Information was obtained on the following potential risk factors: contact with other persons including children; interstate or overseas travel; water exposures; animal exposures, including type of animals, and description of contact/interaction; food preparation, including food hygiene and food handling practices; food consumption, including types of foods and formulas; and parental awareness of health promotion and education initiatives.

\section{Sample size}

A matched design and a case-control ratio of $1: 2$ was selected as the most appropriate strategy in order to maximise the study power. To detect an association with a matched odds ratio of 2.0 at the $5 \%$ significance level with $80 \%$ power (assuming $20 \%$ exposure level among controls), a sample size of 126 cases and 252 controls was required [15].

\section{Analysis}

Case-control sets were included for analysis provided that at least one control was matched for each case. Epi Info Version 6.02 [16] was used to calculate crude matched odds ratios (OR) with $95 \%$ confidence intervals $(\mathrm{CI})$ and two-tailed $P$-values to estimate the association between various potential risk factors and campylobacter illness. Following the univariate analysis, Epi Info 2000 [17] was used to calculate 
adjusted odds ratios by backward stepwise logistic regression of risk factors with a $P$-value $\leqslant 0 \cdot 25$.

\section{RESULTS}

During the study period, 110 cases were referred to this Unit and 571 children registered as possible controls. Of the 110 cases, 104 agreed to participate in the study and were interviewed. After applying the exclusion criteria, 81 cases were included in the analysis. Eighty percent of the cases were interviewed within 7 days of the investigators receiving notification, and $96.3 \%$ were interviewed within 14 days. Following completion of the study, a review of the state-wide notifiable diseases system revealed that $63 \%$ of all eligible notified cases were included in the study. From the total number of controls registered, 144 were included in the study, with 18 cases matched to 1 control, and 63 cases matched to 2 controls.

The demographic characteristics of the cases and controls are shown in Table 1. Slightly more males than females were enrolled in the study, with the majority of subject's aged 12 months or older. The main symptoms reported by the cases were diarrhoea $(98 \cdot 8 \%)$, bloody diarrhoea $(40 \cdot 7 \%)$, and vomiting $(39 \cdot 5 \%)$.

\section{Univariate analysis of risk factors}

One hundred and sixty variables were included in the initial analysis. Potential risk factors for campylobacter illness (i.e. those with a matched odds ratio >1) are shown in Table 2. In regard to animal exposure, ownership of a pet (OR 2.04, CI 1.8-4.13), ownership of pet chickens (i.e. chickens either free-ranging or in a coup and kept for non-commercial egg production) (OR 11.00, CI 1.21-473.06), and ownership of a pet puppy (OR 16.75, CI 3.76-141.66) were significantly associated with illness. The keeping of guinea-pigs was not associated with illness, as was exposure to two or more pet cats. Exposure to animals that had diarrhoea and access of the child to areas in which the pets roamed were also not associated with illness.

Consumption of mayonnaise was the only food item significantly associated with illness (OR 3.87, CI $1 \cdot 48-11 \cdot 21)$. Other foods with a moderately increased risk of illness were softcheese, raw eggs, mutton and bottle fed milk, but these were not statistically significant. In regard to food handling practices, inappropriate hand washing and food thawing, and inadequate cleaning of utensils were non-significantly
Table 1. Demographic characteristics of subjects

\begin{tabular}{lll}
\hline \hline & Cases $(\%)$ & Controls $(\%)$ \\
\hline Sex & & \\
$\quad$ Male & $44(54)$ & $78(54)$ \\
$\quad$ Female & $37(46)$ & $66(46)$ \\
Age & & \\
$\quad 0-11$ months & $15(19)$ & $31(22)$ \\
12-23 months & $36(44)$ & $55(38)$ \\
$24-35$ months & $30(37)$ & $58(40)$ \\
Total & 81 & 144 \\
\hline \hline
\end{tabular}

associated with illness. Insufficient data were obtained on bottle feeding practices and preparation practices for baby food (from cans or jars), and as such, no conclusions could be made about these exposures.

Of the other exposures recorded, travel had an elevated (but non-significant) OR and eating of soil by the child was not associated with illness. However, child contact with other children in nappies (OR 0.44, CI $0 \cdot 20-0.89)$ and attending a childcare centre (OR $0 \cdot 37$, CI $0 \cdot 17-0 \cdot 83$ ) were significantly associated with a decrease in risk of illness. Insufficient data were obtained on child exposure to persons with an illness, particularly a gastric illness, and as such, no conclusions could be made about these exposures.

\section{Multivariate analysis of risk factors}

Of the nine risk factors included in the initial logistic regression model, a significant independent association with illness was found for the following three risk factors: ownership of pet chickens (adjusted OR 11.80), ownership of a puppy (adjusted OR 16.58), and consumption of mayonnaise (adjusted OR 4.13) (refer to Table 3).

\section{DISCUSSION}

This study identified three independent risk factors (exposure to puppies, pet chickens and mayonnaise) for campylobacter infection in children aged less than 3 years. Contact with puppies has been previously reported as being associated with campylobacter illness, however, this appears to be the first report of an association with pet chickens in a developed country. Some of the general risk factors identified in previous case-control studies (e.g. consumption of untreated water, raw milk and undercooked chicken, handling raw poultry, and travel) were not found in this study to be associated with campylobacter illness in infants and young children. This may be explained 
Table 2. Univariate analysis of selected risk factors for campylobacter illness (matched $O R>1$ )

\begin{tabular}{|c|c|c|c|c|c|}
\hline \multirow[b]{2}{*}{ Risk factors } & \multicolumn{2}{|l|}{ No. } & \multirow[b]{2}{*}{$\begin{array}{l}\text { Matched } \\
\text { odds ratio }\end{array}$} & \multirow[b]{2}{*}{$95 \% \mathrm{CI}$} & \multirow[b]{2}{*}{$P$-value } \\
\hline & $\begin{array}{l}\text { Cases } \\
(n=81)\end{array}$ & $\begin{array}{l}\text { Controls } \\
(n=144)\end{array}$ & & & \\
\hline \multicolumn{6}{|l|}{ Pet exposure } \\
\hline Ownership of a pet & $59 / 81$ & $83 / 144$ & $2 \cdot 04$ & $1 \cdot 08-4 \cdot 13$ & $0 \cdot 03$ \\
\hline Ownership of more than one pet & $35 / 59$ & $37 / 83$ & $1 \cdot 67$ & $0 \cdot 72-4 \cdot 23$ & $0 \cdot 26$ \\
\hline Ownership of more than two pets & $18 / 59$ & $17 / 83$ & $1 \cdot 44$ & $0 \cdot 61-3 \cdot 49$ & $0 \cdot 46$ \\
\hline Bird & $11 / 81$ & $12 / 144$ & $1 \cdot 63$ & $0 \cdot 62-4 \cdot 61$ & $0 \cdot 35$ \\
\hline Cat & $19 / 81$ & $32 / 144$ & $1 \cdot 09$ & $0 \cdot 54-2 \cdot 18$ & $0 \cdot 91$ \\
\hline Chickens & $6 / 81$ & $1 / 144$ & $11 \cdot 00$ & $1 \cdot 21-473 \cdot 06$ & $0 \cdot 03$ \\
\hline Dog & $38 / 81$ & $57 / 144$ & $1 \cdot 39$ & $0 \cdot 75-2 \cdot 59$ & $0 \cdot 39$ \\
\hline Kitten (cat aged less than 6 months) & $3 / 81$ & $3 / 144$ & $1 \cdot 67$ & $0 \cdot 21-12 \cdot 17$ & $0 \cdot 89$ \\
\hline Puppy (dog aged less than 6 months) & $18 / 81$ & $3 / 144$ & $16 \cdot 75$ & $3 \cdot 76-141 \cdot 66$ & $<0 \cdot 001$ \\
\hline More than two pet dogs & $10 / 81$ & $7 / 144$ & $2 \cdot 57$ & $0 \cdot 85-9 \cdot 00$ & $0 \cdot 10$ \\
\hline $\begin{array}{l}\text { Never hand washing after pet contact } \\
\text { (never } v s \text {. always) }\end{array}$ & $16 / 36$ & $18 / 64$ & 1.91 & $0 \cdot 47-8 \cdot 78$ & $0 \cdot 48$ \\
\hline \multicolumn{6}{|l|}{ Food handling } \\
\hline $\begin{array}{l}\text { Never hand washing before eating } \\
\text { (never vs. always) }\end{array}$ & $10 / 40$ & $10 / 68$ & $2 \cdot 63$ & $0 \cdot 57-16 \cdot 26$ & $0 \cdot 28$ \\
\hline $\begin{array}{l}\text { Food thawing procedure (room temperature } v s \text {. } \\
\text { refrigeration or microwave) }\end{array}$ & $31 / 76$ & $50 / 141$ & $1 \cdot 25$ & $0 \cdot 63-2 \cdot 47$ & $0 \cdot 59$ \\
\hline $\begin{array}{l}\text { Never wash utensils between use with raw and } \\
\text { cooked foods (never } v \text { s. always) }\end{array}$ & $2 / 70$ & $3 / 133$ & $2 \cdot 00$ & $0 \cdot 14-27 \cdot 59$ & $0 \cdot 86$ \\
\hline \multicolumn{6}{|l|}{ Food consumption } \\
\hline Softcheese & $8 / 77$ & $6 / 143$ & $2 \cdot 31$ & $0 \cdot 70-8 \cdot 19$ & $0 \cdot 19$ \\
\hline Ice-cream & $43 / 77$ & $73 / 142$ & $1 \cdot 11$ & $0 \cdot 59-2 \cdot 07$ & $0 \cdot 84$ \\
\hline Mayonnaise & $17 / 76$ & $11 / 142$ & $3 \cdot 87$ & $1 \cdot 48-11 \cdot 21$ & $0 \cdot 003$ \\
\hline Custard & $33 / 77$ & $54 / 143$ & $1 \cdot 17$ & $0 \cdot 63-2 \cdot 17$ & $0 \cdot 69$ \\
\hline Raw eggs & $3 / 77$ & $1 / 143$ & $5 \cdot 50$ & $0 \cdot 40-275 \cdot 6$ & $0 \cdot 30$ \\
\hline Microwaved eggs & $9 / 77$ & $10 / 143$ & $1 \cdot 61$ & $0 \cdot 52-5 \cdot 06$ & $0 \cdot 48$ \\
\hline Ham & $36 / 76$ & $57 / 143$ & $1 \cdot 40$ & $0 \cdot 73-2 \cdot 70$ & $0 \cdot 35$ \\
\hline Chicken (at home) & $39 / 63$ & $77 / 120$ & $1 \cdot 02$ & $0 \cdot 47-2 \cdot 27$ & $0 \cdot 90$ \\
\hline Pate & $3 / 77$ & $4 / 143$ & $1 \cdot 22$ & $0 \cdot 18-7 \cdot 40$ & 0.89 \\
\hline Pork & $15 / 75$ & $22 / 143$ & $1 \cdot 46$ & $0 \cdot 59-3 \cdot 46$ & $0 \cdot 49$ \\
\hline Bacon & $28 / 77$ & $43 / 143$ & $1 \cdot 32$ & $0 \cdot 68-2 \cdot 55$ & $0 \cdot 46$ \\
\hline Mutton & $25 / 76$ & $29 / 143$ & $1 \cdot 87$ & $0 \cdot 98-3 \cdot 81$ & $0 \cdot 06$ \\
\hline Mince & $46 / 76$ & $81 / 143$ & $1 \cdot 16$ & $0 \cdot 60-2 \cdot 29$ & $0 \cdot 75$ \\
\hline Salads & $31 / 77$ & $60 / 143$ & $1 \cdot 03$ & $0 \cdot 53-2 \cdot 00$ & 0.72 \\
\hline Raw vegetables & $23 / 77$ & $34 / 143$ & $1 \cdot 41$ & $0 \cdot 69-2 \cdot 88$ & $0 \cdot 39$ \\
\hline Milk & $20 / 72$ & $36 / 139$ & $1 \cdot 07$ & $0 \cdot 37-3 \cdot 09$ & $0 \cdot 94$ \\
\hline Milk (bottle fed only) & $16 / 49$ & $11 / 84$ & $3 \cdot 29$ & $0 \cdot 71-19 \cdot 81$ & $0 \cdot 16$ \\
\hline \multicolumn{6}{|l|}{ Other exposures } \\
\hline Travel - intra/interstate, overseas & $5 / 81$ & $2 / 144$ & $3 \cdot 80$ & $0 \cdot 67-44 \cdot 68$ & $0 \cdot 15$ \\
\hline Unreticulated water supply & $7 / 81$ & $10 / 144$ & $1 \cdot 29$ & $0 \cdot 41-3 \cdot 77$ & $0 \cdot 80$ \\
\hline $\begin{array}{l}\text { Use of animal manure or processed fertilisers } \\
\text { in garden }\end{array}$ & $5 / 71$ & $9 / 143$ & $1 \cdot 33$ & $0 \cdot 30-5 \cdot 36$ & $0 \cdot 92$ \\
\hline Child access to areas of fertilizer use & $12 / 70$ & $18 / 144$ & $1 \cdot 67$ & $0 \cdot 60-4 \cdot 28$ & $0 \cdot 41$ \\
\hline Use of dynamic lifter & $7 / 71$ & $14 / 144$ & $1 \cdot 00$ & $0 \cdot 33-2 \cdot 80$ & 0.81 \\
\hline
\end{tabular}

by the age of the cases enrolled in our study and a possible lack of study power.

Healthy dogs and puppies have been shown to have campylobacter carriage rates of between $5 \%$ and $29 \%[18,19]$ and ownership of a pet puppy has been previously identified as a risk factor [5, 7, 11]. Our study supports this association and confirms that infants and young children are at particular risk of infection. Poor hygiene in this age group and closer than normal contact with pets may partly explain this 
Table 3. Multivariate analysis of selected risk factors for campylobacter illness

\begin{tabular}{lllr}
\hline \hline Risk factor & Adjusted odds ratio & $95 \% \mathrm{CI}$ & $P$-value \\
\hline Ownership of pet chickens & $11 \cdot 80$ & $1 \cdot 37-101 \cdot 75$ & 0.025 \\
Ownership of a puppy & 16.58 & $3 \cdot 73-73 \cdot 65$ & $<0.001$ \\
Consumption of mayonnaise & $4 \cdot 13$ & $1 \cdot 61-10.59$ & 0.003 \\
\hline \hline
\end{tabular}

increased risk. Having a household pet (including a puppy) with diarrhoea has also been described as a risk factor for campylobacter infection [10, 11]. However, in our study only 2 of the 18 case households reported puppies with diarrhoea in the week before onset of illness in the child. Interestingly, 15 of the 18 cases $(83 \%)$ regularly played in an area of the home in which the puppy also had access.

The association of pet chickens with campylobacter infection in young children has been previously reported, but this has been in developing countries and for situations in which the chickens were allowed access within the home [13, 14]. Also, daily contact with chickens in a farm setting has been recently reported as a risk factor [20]. This source of exposure is biologically plausible, as campylobacters have been shown to be excreted in the faeces of healthy chickens $[18,21]$ and have been isolated from the feathers of healthy chickens [22]. The route of transmission of infection to young children is probably similar to that for puppies and young children.

The significant association between consumption of mayonnaise and campylobacter illness is difficult to explain in this age group. This association is biologically plausible as one of the ingredients of mayonnaise is raw eggs and healthy chickens are known to excrete campylobacter [21]. However, there have been no reported outbreaks of campylobacter infection associated with contaminated or cracked eggs, or egg products. In addition, studies have shown that $C$. jejuni is rarely isolated from the shell surface or egg contents of chickens faecally excreting this organism [21]. It is most likely that this association occurred through random error or some type of systematic error.

The protective effect shown for children who had contact with other children in nappies and for children who attended a childcare centre was unexpected, as it has been reported that person-to-person transmission of campylobacter is uncommon in adults [23, 24]. Furthermore, immune mechanisms following campylobacter infection are not well understood, however, it has been suggested that lack of immunity in humans may be due to type-restricted protective immunity, poorly immunogenic protective antigens, or short life of the induced antibodies [25]. Random error could also account for these findings.

In this study, ownership of pet puppies and pet chickens, or consumption of mayonnaise could account for $41(51 \%)$ of the 81 cases at most, with significant risk factors for the remaining cases not identified. This suggests there was probably insufficient study power to detect further independent risk factors for campylobacter infection in infants and young children, including the failure to find a significant association between illness and other food and animal exposures, and poor food hygiene and handling practices among respondents.

Alternative explanations for the observed results of this study include random error, selection bias, observation bias and confounding. However, given the magnitude of the associations for exposure to pet chickens or pet puppies and the low probability of these associations occurring if the null hypothesis were true, it is unlikely that these alternative explanations could totally account for the observed results. Selection bias, if any, was considered to be minimal because the methods used to select the cases and controls were not related to any specific exposures, and were completely independent of each other.

Attempts were made to minimize observation bias during the design of this study. This included limiting the recall period to 7 days prior to illness (cases) or interview (controls) and enforcement of the exclusion criteria. In an attempt to reduce interviewer bias, only one trained interviewer was used in this study. However, interviews were not conducted blindly with cases and controls, and as such interviewer bias cannot be excluded as having an influence on our findings. Finally, we suggest that it is unlikely that confounding by unknown risk factors, which were not measured in the study or controlled for during the analysis, would be totally responsible for the magnitude of the observed association with ownership of puppies or chickens. 
In conclusion, the evidence presented in this study supports a likely association between campylobacter infection and ownership of pet puppies and pet chickens. Consequently, we propose that children aged less than 3 years are at risk of campylobacter infection if residing in a household which has puppies or chickens as pets.

\section{ACKNOWLEDGEMENTS}

We thank all the subjects who participated in the study, the medical practitioners who notified the cases, the Child Health Clinics for enrolling controls, and the pathology laboratories who performed analysis of the stool samples. Funding for the study was provided by the Queensland Health Primary Health Care Public/Private Sector Demonstration Program. We thank Dr Ilona Papajcsik for obtaining the funding and scientific advice, and Stephen Pollard, project officer.

\section{REFERENCES}

1. Thompson J, Lin M, Halliday L, et al. Australia's notifiable disease status, 1998. Comm Dis Intell 1999; 23: 277-305.

2. Tauxe RV, Hargrett-Bean N, Patton CM, Wachsmuth IK. Campylobacter isolates in the United States, 1982-1986. MMWR 1988; 37: 1-13.

3. Neal KR, Slack RCB. The autum peak in campylobacter gastroenteritis: are the risk factors the same for travel and UK acquired campylobacter infections? J Publ Hlth Med 1995; 17: 98-102.

4. Kapperud G, Skjerve E, Bean NH, Osteroff SM, Lassen J. Risk factors for sporadic campylobacter infections: results of a case-control study in southeastern Norway. J Clin Microbiol 1992; 30: 3117-21.

5. Neal KR, Slack RCB. Diabetes mellitus, anti-secretory drugs and other risk factors for campylobacter gastroenteritis in adults: a case-control study. Epidemiol Infect 1997; 119: 307-11.

6. Deming MS, Tauxe RV, Blake PA, et al. Campylobacter enteritis at a university: transmission from eating chicken and from cats. Am J Epidemiol 1987; 126: 526-34.

7. Eberhart-Phillips J, Walker N, Garret N, et al. Campylobacteriosis in New Zealand: results of a casecontrol study. J Epidemiol Commun Hlth 1997; 51: 686-91.

8. Hopkins RS, Olmsted R, Istre GR. Endemic Campylobacter jejuni infection in Colorado: identified risk factors. Am J Publ Hlth 1984; 74: 249-50.

9. Ikram R, Chambers S, Mitchell P, Brieseman MA, Ikram OH. A case-control study to determine risk factors for campylobacter infection in Christchurch in the summer of 1992-3. N Z Med J 1994; 107: 430-2.
10. Adak GK, Cowden JM, Nicholas S, Evans HS. The Public Health Laboratory Service national case-control study of primary indigenous sporadic cases of campylobacter infection. Epidemiol Infect 1995; 115: 15-22.

11. Saeed AM, Harris NV, DiGiacomo RF. The role of exposure to animals in the etiology of Campylobacter jejuni/coli enteritis. Am J Epidemiol 1993; 137: 108-14.

12. Stafford R, Tenkate T, McCall B. A five year review of campylobacter infection in Queensland. Comm Dis Intell 1996; 20: 478-82.

13. Pazzaglia G, Bourgeous AL, Araby I, et al. Campylobacter-associated diarrhoea in Egyptian infants: epidemiology and clinical manifestations of disease and high frequency of concomitant infections. J Diarr Dis Res 1993; 11: 6-13.

14. Grados O, Bravo N, Black RE, Butzler JP. Paediatric campylobacter diarrhoea from household exposure to live chickens in Lima, Peru. Bull WHO 1988; 66: 369-74.

15. Schlesselman JJ. Case-control studies: design, conduct, analysis. New York: Oxford University Press, 1982: 354.

16. Dean AG, Dean JA, Coulombier D, et al. Epi Info, Version 6: a word processing, database, and statistics program for epidemiology on microcomputers. Atlanta: Centers for Disease Control and Prevention, 1994.

17. Dean AG, Arner TG, Sangam S, et al. Epi Info 2000, a database and statistics program for public health professionals for use on Windows 95, 98, NT, and 2000 computers. Atlanta: Centers for Disease Control and Prevention, 2000.

18. Svedhem A, Kaijser B. Isolation of Campylobacter jejuni from domestic animals and pets: probable origin of human infection. J Infect 1981; 3: 37-40.

19. Hald B, Madsen M. Healthy puppies and kittens as carriers of Campylobacter spp., with special reference to Campylobacter upsaliensis. J Clin Microbiol 1997; 35: 3351-2.

20. Studahl A, Andersson Y. Risk factors for indigenous campylobacter: a Swedish case-control study. Epidemiol Infect 2000; 125: 269-75.

21. Doyle MP. Association of Campylobacter jejuni with laying hens and eggs. Appl Environ Microbiol 1984; 47: 533-6.

22. Gregory E, Barnhart H, Dreeson DW, Stern NJ, Corn JL. Epidemiological study of Campylobacter spp. in broilers: source, time of colonization, and prevalence. Avian Dis 1997; 41: 890-8.

23. Norkrans G, Svedham A. Epidemiological aspects of Campylobacter jejuni enteritis. J Hyg 1982; 89: 163-70.

24. Skirrow MB, Blaser MJ. Campylobacter jejuni. In: Blaser M, Smith P, Ravdin J, Greenberg H, Guerrant $\mathrm{R}$, eds. Infections of the gastrointestinal tract. New York: Raven Press, 1995: 825-48.

25. Newell DG, Nachamkin I. Immune responses directed against campylobacter jejuni. In: Nachamkin I, Blaser M, Tompkins L, eds. Campylobacter jejuni: current status and future trends. Washington, D. C.: American Society for Microbiology, 1992: 201-6. 